\title{
A STUDY ON PURE WORD-DEAFNESS
}

\author{
BY \\ R. E. HEMPHILL and E. STENGEL \\ (RECEIVED 4TH JANUARY, 1940) \\ From the Bristol City and County Mental Hospital
}

ONE of the speech disorders which in the past was studied with great interest is the so-called pure word-deafness. In recent years, however, it appears to have been somewhat neglected, perhaps because the condition is rare and does not appear to fit in well with the modern conceptions of aphasia (Jackson, Marie, Head, Goldstein). Pure word-deafness was described and defined for the first time by Lichtheim (1885) as a speech disorder in which the ability to understand spoken language, to repeat spoken words, and to write from dictation were lost, and, at the same time, the ability to speak, write, and read spontaneously was preserved. In the picture of pure word-deafness there were no paraphasias and the inner speech remained undisturbed. A lack of attention to acoustic sensations was regarded as typical. Lichtheim's observations were confirmed by Wernicke (1874), Wyllie (1894), Ballet (1901) et al., Arnaud (1887), who named the disorder "surdite verbale brute," pointed out that it was characterized by an impairment of the gross hearing of words. According to him the actual understanding of the sounds of words was disturbed, a fact confirmed by other observers. In some of the cases described pure word-deafness seemed to develop from a typical auditory aphasia. In these cases the purity of the picture was impaired by the existence of paraphasias and other signs of disturbance of the inner language. The question whether defects of hearing as well, caused by disturbance of the inner ear could give rise to the condition was discussed by some authors, who expressed the view that labyrinthine lesions might sometimes cause the symptoms of pure word-deafness. This view, however, was questioned when, in a case where an existing bilateral lesion of the labyrinths had been regarded as the cause of pure word-deafness (Freund, 1903), the post-mortem examination revealed a tumour involving the first temporal convolution of the left hemisphere. As the ordinary technique for the investigation of the hearing capacity cannot be employed in pure worddeafness, the use of the Bezold-Edelmann's continuous series of tuning forks was recommended, and it was pointed out that at least that portion of the tone scale known as speech sext (Bezold, 1903), with a proportion of tones for a considerable distance above and below, must be intact before the diagnosis of pure word-deafness could be justifiably made (Bonvicini, 1905). Although we do not propose to quote in detail the bulk of the literature on this subject, we 
can assert that, as Weisenburg and MacBride (1935) pointed out, in all cases reported, the purity of the word-deafness was impaired either by disturbance of the hearing capacity or of the inner language.

As to the position of pure word-deafness in the general scheme of aphasia, it is noteworthy that even Lichtheim admitted that preservation of the inner language was an objection to regarding pure word-deafness as an aphasia proper. Nevertheless, he found it necessary to define it as an aphasia as it had so many features in common with the aphasic speech disorders. This view was favoured by the observation mentioned before that pure word-deafness may appear in the course of recovery from typical auditory aphasia. Goldstein (1927) considers that the essence of pure word-deafness lies in the incapacity to comprehend the tones as characteristic speech sounds, although these tones have been perceived. He compares the patient suffering from pure word-deafness to an individual who is in a country where the language is entirely unknown to him. Such a person would not only fail to understand the meaning of the words he hears, but would be unable even to appreciate the combination of sounds as words or sentences. Some workers refused to recognize pure word-deafness as an aphasia at all. Pierre Marie (1906) asserted that he had never seen a case. Van Woerkom (1925) and Mourgue (1920) regarded this symptom as a theoretical construction, and in Head's (1926) scheme of speech disorders there is no space for pure word-deafness.

We have been fortunate enough to encounter and study a case in which the characteristic picture of pure word-deafness was present and was associated with another symptom of additional interest.

Henry G., aged 34, general labourer, was admitted to the Bristol Mental Hospital on 10th April, 1939. On 11th February, 1939, he had been admitted to the Bristol General Hospital in a state of unconsciousness, following a fall from a 'bus. After three days he became clearer and he then gave the impression of being totally deaf. However, from his own statements, made as soon as he had become quite clear in mind, it was evident that his deafness was not of an ordinary character. Otological investigation, to which we will refer later, revealed that there was no gross inability to hear sounds.

After the acute effects of the accident had subsided, the patient was admitted as a voluntary patient to the mental hospital. He described the defect of hearing as an inability to understand spoken words, but, at the same time, insisted that he could hear sounds and noises as well as before the accident. This description of his disability has not changed materially from the beginning. At this point the only reference we will make to his physical state is that of the otological examination. This was conducted by Mr. A. T. M. Wright. The audiometer was employed, as the ordinary methods for testing hearing could not be used in this particular case. The audiogram (air conduction) which we reproduce shows, for the left ear a slight amount of hearing loss in the upper frequencies, and practically normal hearing throughout the scale for the right ear. If the tracings for each ear are compared with the typical tracings of a deaf person, one sees that the impairment of the hearing in our patient was practically negligible. On the average, patients with such an amount of hearing loss show hardly any practical difficulty in normal hearing.

The prominent feature of the patient's disability was the fact that he could not understand spoken language. Investigations into his speech showed the following:

Articulated Speech.- He talked fluently, and without conversational mistakes of a pathological nature. There were no paraphasias and no errors of grammar beyond 
what is common for his particular dialect and standard of education. He was, however, noticeably loquacious, especially during the first three months after the accident. His wife confirmed this impression and said that he was much more talkative than he had ever been before. In this way his condition reminded one of the logorrhora seen in auditory aphasia. This feature tended to diminish as time went on. He had no difficulty in finding words without circumlocution and in forming sentences. There was no dysarthria.

Reading.- He could read correctly and showed that he could understand what he read to himself. He obeyed written orders without errors, even if complicated, such as Head's hand-eye-ear test and other more difficult commands. His response to the commands was equally correct whether he read aloud or to himself. If a number of

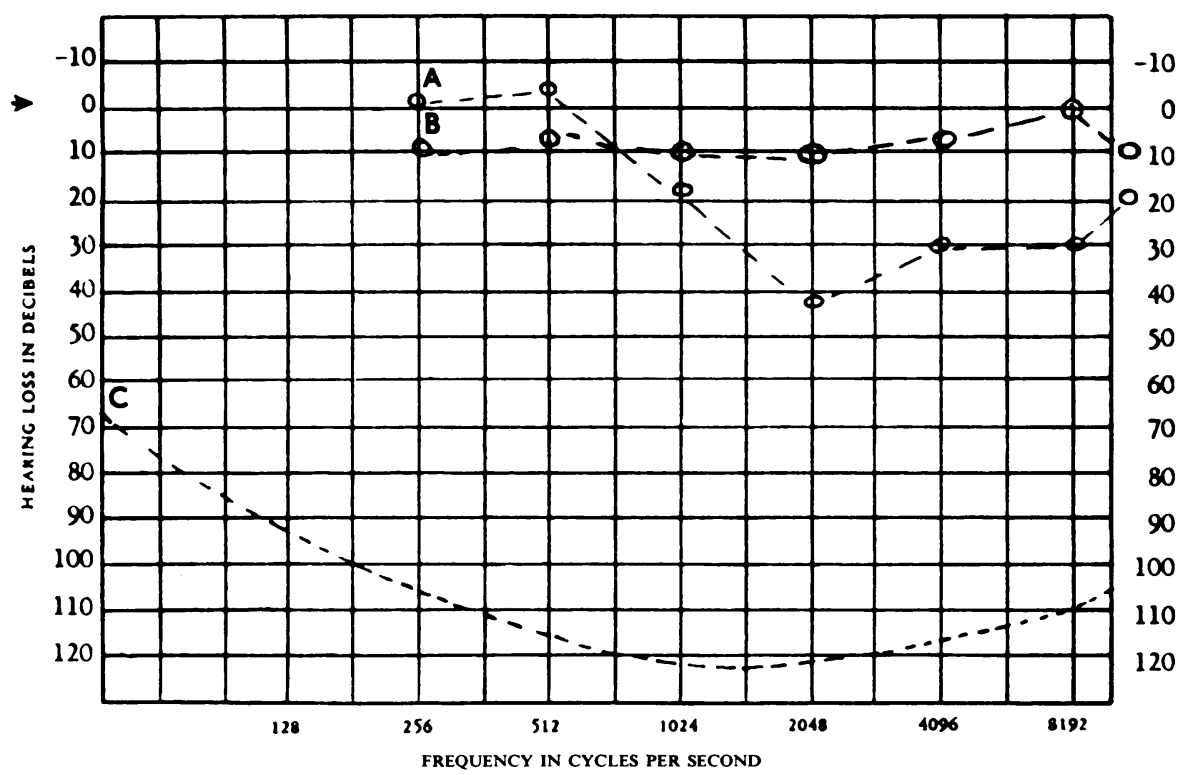

Fig. 1.-Audiometer tracing.

The $\mathrm{B}$ dotted line is the record of the right, the $\mathrm{A}$ of the left ear. The $\mathrm{C}$ dotted line represents the tracing of a deaf person with total loss of serviceable hearing. $O$ : Average normal hearing.

objects were placed on the table and he were requested, in writing, to name any of them, he did so without error.

Writing.-He could write correctly and his spelling was good. His writing contained no more grammatical errors than one could expect from one of his education, and he could write a précis of what he read in print.

Other Intellectual Functions.- He could count correctly and could do simple arithmetic. His drawings were poor, but did not suggest any special disability in this respect. Plan drawing was correctly performed and his orientation in his surroundings was not disturbed. There was no autotopagnosia.

As stated before, the disturbance of speech was confined to the understanding of spoken words. We propose to illustrate this kind of disorder and the patient's attitude towards it by reporting a number of interviews we have had with the patient. These results will be presented as if the interviews were continuous and took place on one day. It seems that, by so doing, a more comprehensive picture may be obtained. Naturally the patient tended to become tired and could not be examined satisfactorily for a long period at one time. 
(What is your name?) "Voice comes but no words. I can hear, sound comes, but words don't separate." - (How are you?) "That is letters what you are saying." (Show your tongue.) "I can't get it. I can hear your voice coming, but it does not finish. Your voice is dead plain." - (Do you feel better?) " Feeling better? I think so." - (How long have you been here?) "Can't get it." - (Close your eyes.) "Can't get it." - (Are you a burglar?) " Can't get it." - (There will be no war.) " That did not separate at all." - (God save the King.) "I can hear you say something." He recognized the melody of the national anthem immediately. The patient added: "There is no trouble at all with the sounds. The sounds come." - (Have you a family?) "Have you something - I could not get the rest." - (Have you children?) "It does not come. The words split up, it does not finish." - (What time is it now?) "What time is it now, did you say?" - (Proverb: early to bed, etc.) "Something about only to-day and something about to-morrow." - (Have you slept well?) " There was four words there. I can hear, but I cannot understand it."

The patient stressed spontaneously that he did not try to lip-read. He added: "I wanted to hear from there. (Pointing to his ears.) I don't want to watch your mouth."

He could imitate melodies without words, provided they did not contain very high tones. He showed a good sense of rhythm. He rarely made a mistake in repeating common sequences, as the alphabet or the early integers. If questioned about his address or his children or asked to repeat very familiar words, he frequently answered correctly. In fact, his understanding for things close to his heart and interests was better than for those of a general nature.

Although he occasionally appeared to understand better when the voice was raised, as a rule there seemed to be no relation between the loudness of speech and his ability to interpret it. The impression, occasionally received, that he was deaf was usually contradicted later in the examination, when the patient might understand quite readily some words spoken softly which he had previously ignored. Sometimes, if one spoke slowly and separated every syllable, articulating clearly, he seemed to understand more clearly, but generally even monosyllabic and short words could not be understood at all. It made no difference to his understanding if the sentences were sung in a well-known melody.

Single letters were not always understood well, as follows: (A) "A." - (I " U." (O) "U." - (O) "Oh." - (X) "U." - (Y) a sound very similar to U, but with a coughing intonance. - (M) coughing sound. - (I) " $\mathrm{Hm} "$ ": hum of assent.

Syllables and short words: (Au) "We." - (Au) "Hop." - (H) "Hu." - (If) “Bum." - (And) "And." - (See) "Tea." - (Cup) "Cup." - (House) "If." (Buttercup) "That is a longish word." - (Schoolboy) "Teatime." - (Schoolboy) "Feeding, did you say?" - (Schoolboy) "That sounded like tea something." (Match) "All that came was mwoe." - (Town) "Raw, row." - (Bristol) " That's going misda." - (Debt, debt, debt) " That sounds like if, if, if."

When he learned from written information what was really said he was very surprised. When asked if and how he heard the words he spoke himself, he replied: "When I say book, I hear book. Every word I am saying is separate." At another time, however, he indicated that he heard his own words in a similar way to those of other people. (It is obviously impossible to expect the patient to give a clear answer to the question of whether he hears his own spoken words in the form of normal speech or not, as he is quite aware that what he says is correct and he anticipates in his mind from past experience the sounds of the words, with which he has been familiar since he learned to speak.)

It often happened that at a later time in the examination the patient produced some word he had failed to repeat previously. Probably it was by the same process that at times he could eventually repeat a word that had been repeated to him without success several times. He often produced a word which seemed to be the result of a contamination of the word just heard with another, heard some time ago, e.g. (Ashtray) 
"Can't get it." - (Medicine bottle) " Matches bottle." - (Matches) "Ashtray." (Rubber) "Rubber" - (Rubber) "Something there with a ru." - (Rule) "Rule, that's what it sounds like." - (Rubber) "It sounds more like ruler." - (The large key) "Did you say ashtray?"

Very much better results were obtained if the patient had a knowledge of the possible alternatives to the questions and if the number of the alternatives was limited. This was shown by the following experiments: A number of different objects were laid out on the table in front of the patient. He was requested to pick up whatever object was named. This was the result of one such test: (Take the key) key taken. (Cigarette) "I am not sure." - (Cigarette case) cigarette taken. - (Matchbox) watch taken. - (Inkpot) "It comes in two syllables." - (Handkerchief) no response. (Where is the ashtray) "I don't get it. I hear it, but it breaks up." - (Take the matches) "That was altogether foggy, that came all on top." - (Penny) penny taken.

Another experiment, similar to that above, was performed. In this the patient was presented with a list of names written on paper. He was then asked to repeat words taken from the list at random by the examiner. (Devon) "Devon." - (Lincoln) "Leicester." - (Gloucester) "None of them. I heard dista." - (London) " Clevedon." - (Salisbury) "I heard lafte." - (Leicester) "Sounded like Bristol." (London) "Diwan, Devon?" - (Leeds) "Leeds." - (Birmingham) " That sounds like Leeds." - (Oxford) " Lincoln." - (Lincoln) " Lincoln." - (Warwick) " Birmingham, did you say? I heard Bram." - (Salisbury) "It comes like bobo." (Bristol) " Bristol." - (Bristol) " Leicester." - (Bristol) " Lincoln." - (Oxford) "Could not get it. It appears with a B in front." This examination showed that the same word could produce very different sensations in the patient on different occasions.

Usually the patient appeared to understand conversation better when it concerned his normal sphere of life. Accordingly he appeared to understand his wife and friends more easily than strangers. The following is a specimen of a conversation overheard while his wife was visiting him at the hospital: (Do you want anything brought in to-morrow?) " No, I don't want anything brought to-morrow." - (I might go out on Monday and might take the children on the downs.) "I did not get that." - (I have dug up all the garden) "You have dug up all the garden." - (I left Sam out on Redcliff Hill) "I did not get that." Sometimes the patient did not catch the full meaning of all the words, even if his answers seemed to suggest that he did, e.g. (Do you want a pair of socks brought in to-morrow?) " No. I want only cigarettes." (What did I say?) " Do you want something brought in to-morrow, but I could not get what."

Very often the patient showed the peculiarity of repeating questions before answering, reminiscent of echolalia, e.g. (How long have you been here?) " How long have I been here? Since yesterday." - (Where did you go to school?) "Where did I go to school? In Bristol." - (How did you sleep last night?) "Did I sleep? Not as well as before."

The patient often complained that what he heard sounded like a foreign language, unknown to him. Summarizing his descriptions of speech as he heard it during repeated examinations and during his daily experience, we found the following to be characteristic and often repeated. "I cannot get it. It does not finish. It's one on top of the other. The words split themselves up. I hear what you are saying, but the pronunciation does not finish. The voices seem to be as clear as it should be. I can hear you quite plainly, but all come on top. I can hear you dead plain, but I cannot get what you say. The noises are not quite natural. I hear your voice, but not the words. I can hear but not understand. It does not pronounce itself."

In contradiction to what has been described by some authors we noticed no lack of attention during conversation, rather the reverse. The patient was always ready to try to understand and to notice changes in tone or rhythm or technique. However, it is certain that his reaction to unexpected sounds, which would have attracted the 
attention of normal people, was either lacking or inadequate. He did not turn in response to a shout or clapping of hands or a commotion in the ward, although he was aware that these sounds had been caused. This is borne out by the fact that he could recognize members of the nursing staff by their footsteps. The great importance of this particular defect is demonstrated by the following occurrence. The patient was observed proceeding one morning along the main road of the hospital. He made no effort to get out of the way of a lorry behind him in spite of the loud warning of the horn. That he heard the horn and recognized its character is certain, for he admitted as much with considerable heat when he was forbidden, for his own safety, to walk alone on the main road. It was obvious from his action at the time that when he heard the motor horn he did not react as if it were a sound of warning. This behaviour is of interest in connection with a further symptom.

This special symptom was observed from the beginning and was present at every subsequent examination; that was an alteration of the normal reaction to painful stimuli. Thorough and repeated examination of superficial as well as deep sensibility revealed none of the usual forms of disturbance. What was abnormal was the lack of the normal reaction to pain. When the patient was suddenly pricked, even very strongly, he failed to withdraw the part injured. There appeared to be a lack of the normal reaction of defence and flight from danger. He admitted that he could feel the painful stimulus for what it was. This abnormal reaction was the same irrespective of where the stimulus was applied. One felt at first that he was inattentive to painful stimuli, but in the course of the examination it became obvious that there was no real lack of attention. During the examination the patient never failed to report on every single sensation and to describe correctly whether it was painful or whether it was innocuous. The absence of any defence or withdrawal reaction was clearly shown when a strong, painful sensation was applied by surprise, e.g. when the examiner, standing behind the patient, suddenly pricked his hand or neck. When the patient was threatened with the first he made no effort to guard himself or to withdraw his head, nor did he show any instinctive combative reaction. Similarly, he appeared to be quite disinterested when a match was struck close to his face or eyes. He showed the same lack of reaction to unexpectedly loud noises or strong flashes of light. This corresponded to the failure to react to unexpected and dangerous acoustic stimuli referred to above.

The patient soon discovered that the examiners were interested in the way he reacted to painful stimuli. He accordingly tried to explain his reactions by such expressions as: "I am not a man who cannot stand pain," or "I am used to that because I have worked on the road," or "Labourers are always hurting themselves; we don't take any notice of it." On the other hand, his wife assured us that he had always been susceptible to pain and had reacted violently whenever his children pricked or pinched him in play.

Physical State.-General condition: well-built, muscular man, showing an old appendicectomy scar. Heart and arteries normal. Blood pressure 160/110. Small degree of emphysema, lungs otherwise healthy. Small epigastric hernia. Other systems normal. Urine normal. Wassermann and Meinicke reactions in blood normal.

Skull.-Moderate tenderness, most marked on the left temporal region. X-ray examination: fine crack in the squamous part of the left temporal bone, running upwards and slightly backwards through the middle of the squama for about 2 in. A skiagram taken two months later showed a faint crack in the left petrous bone.

Eyes.—Left eye blind (cataract). Right eye, normal vision, visual field normal, reaction of the pupil to light and convergence normal.

Otological Findings. - The results of the audiometer test have been reported above. The usual examination with tuning forks showed no abnormality. Labyrinthine investigations: no spontaneous nystagmus, no vertigo, no tendency to fall, Barany's pointing test normal. Examination on the rotating stool revealed normal, but obviously 
reduced reactions. Syringing produced normal reactions on the right ear, reduced reactions of a normal type on the left side.

Central Nervous System.-Cranial nerves showed no pathological signs, apart from those above mentioned. Trunk: abdominal reflex present and equal. Muscular power normal. Upper extremities: tendon reflexes brisk on both sides. Muscular power, tonus, all forms of sensibility, normal; no ataxia. Lower extremities: knee and ankle-jerks exaggerated. Variable patellar clonus on the right side, no ankle clonus, no extensor plantar reflex. Oppenheim's sign negative. No disorder of muscular power and of tonus. All forms of sensibility normal. No ataxia. Romberg's sign negative. Gait: patient walks on a wide base rather clumsily, but without definite ataxia.

\section{Summary of the case history}

A man of 34 was admitted to hospital following a serious head injury. When the concussion had subsided, he showed a disturbance of understanding of spoken language. There was no other sign of a gross abnormality of the central nervous system. X-ray examination revealed a fissure of the left squama ossis temporalis and a faint crack of the left temporal bone. There was a reduced reaction to left-sided labyrinthine stimuli. The hearing proper was intact except for a slight impairment of appreciating high tones with the left ear. The patient stated that he could hear noises, but could not understand spoken language. He said spoken language sounded as strange, as if he were hearing a foreign language unknown to him. It was amply proved that what the patient heard differed considerably from the normal sounds of speech. The patient could not hear spoken words correctly, nor could he write to dictation. There were no other signs of speech disorder apart from a certain logorrhœa in the early stages of the illness.

His reaction to unexpected acoustic stimuli was inadequate. He did not show the normal reactions of turning away from or towards the source of sounds, but there was no disorder of attention during conversation. Also he did not show the normal reactions of withdrawal and defence to painful stimuli, nor to visual stimuli which usually give rise to such reactions, nor did he respond adequately to warnings of danger. At the same time, there was no disturbance of sensibility. The patient tried to rationalize this lack of reactions. During the time of observation, extending over half a year, the symptoms did not change materially.

Diagnosis.-The prominent features of this case corresponded with the pure word-deafness as described by Lichtheim. The inability to perceive spoken words correctly, as observed in this patient, has been shown in many cases and has given rise to the term "word-sound-deafness." Besides the pure worddeafness, there was a second symptom, first described by Schilder and Stengel in 1928 as " asymbolia for pain." This symptom consists in lack of adequate reactions to painful stimuli which are obviously perceived correctly by the patient as pain. As in other cases showing this symptom, he also lacked the appropriate reactions to strong acoustic and visual stimuli unexpectedly applied. The diagnosis, therefore, is one of pure word-deafness combined with asymbolia for pain. 


\section{Discussion}

The case described belongs to that group of cases of pure word-deafness in which the inner language is totally unaffected. It has been shown that the very slight lesion of the auditory apparatus cannot be held responsible for the symptom of pure word-deafness. Our case seems to confirm what others have suggested, that in a number of the cases of pure word-deafness there is some defect of the auditory apparatus. One finds the cases mentioned in the literature falling into two groups, namely, those that have developed from an auditory aphasia and those that have not. We cannot say with certainty to which group our patient belonged, for obviously examination was not possible in the early days after his accident, so that one cannot entirely exclude the possibility that an auditory aphasia existed for some days first. In this connection it was noted that the patient exhibited a volubility reminiscent of a logorrhœa, which might be regarded as being the last trace of an auditory aphasia. His tendency to repeat questions and commands is similar to what can be observed in the stages of recovery of pure echolalia in aphasics.

As in cases described by others, our patient showed that he could not perceive words naturally. But, as we have shown in the description of the case, this aberration of perception is totally different from what is found in an ordinary deaf person. The very slight loss of hearing as found in our patient by itself would never have caused such distortion of heard language as he evidently experienced. Our patient described what he heard as something strange and unnatural, but he insisted and proved that he could hear, and his whole attitude was different from that of a deaf person. Hoff and Silbermann (1933) have found that certain patients suffering from lesions of the left temporal lobe complained that heard speech had a strange quality not experienced by them before the illness, which the authors were prompted to name " depersonalization of language." This is reminiscent of what our patient described himself.

The physical examination suggested a slight affection of the left labyrinth. The tinnitus was in keeping with a lesion of this sort, as was the result of the audiometer test. However, similar tracings with the audiometer are obtained where the lesion is in the temporal lobe (Silbermann and Tamari, 1937). The presence of tinnitus in itself cannot be regarded as symptomatic of lesions of the labyrinth, as Frazier and Rowe (1934) have shown. It was present in the majority of their 53 cases with verified tumours of the temporal lobe. It is therefore possible that there yas a lesion of the left temporal lobe (as has been found in many cases of pure word-deafness), co-existing with that of the labyrinth. The fact that a fissure through the middle of the squama of the left temporal bone could be demonstrated also points to this possibility, as this fissure extended to the level of the middle of the first temporal convolution, where lesions have been found in pure word-deafness. It is, therefore, not unreasonable to conceive the possibility of there being a cortical lesion causing the pure word-deafness, more especially as the other symptom of the case can only be explained by a cortical lesion. Once more it is important to remember 
the lesson taught by Freund's case, where the clinical observer first tried to attribute the pure word-deafness to the existing labyrinthine lesion alone, but where the post-mortem examination revealed that a left-sided temperosphenoidal tumour was the real cause of the symptom. From this experience we learn that in trying to explain a rare clinical event, such as pure word-deafness, we need not shrink from assuming an uncommon combination of causes.

Besides the pure word-deafness a second important symptom has been described in our patient: this is what has been called asymbolia for pain. This symptom consists in a loss of adequate reactions to painful and other sudden stimuli, such as a loud noise or a flash of light. The patients so described showed no disturbance of sensibility, but they failed to make the usual efforts of withdrawal or defence. Some of them even showed a paradoxical reaction in which the reactive movement was in the direction of the source of a danger that a normal individual would instinctively associate with a pain suddenly inflicted on the body from without, or an unexpected loud noise or a flash of light. As pointed out by Schilder and Stengel (1928), this behaviour bears a resemblance to some of the reactive movements seen in catatonic conditions. It is, of course, not suggested that any causative factor common to both conditions can be assumed. It could be argued, perhaps, that what has been called asymbolia for pain is nothing but an hysterical phenomenon, especially if it follows an accident. However, the symptom has been undeniably demonstrated in cases where there were gross organic lesions of the brain with a certain consistent localization. This symptom does not resemble any recognized hysterical manifestation and it differs markedly from the hysterical anæsthesias in that in this case the patient insists that his feeling is intact and endeavours to deny or explain away his abnormality. This behaviour is essentially opposed to the attitude of the hysteric, who prefers to demonstrate his disability.

In a number of cases asymbolia for pain has been observed combined with auditory aphasia and only in a few cases without this complication. Potzl and Stengel (1937) have reported a case in which asymbolia for pain was associated with the so-called conductionaphasia, i.e. a form of auditory aphasia in which an ability to repeat heard words is prominent. It is of interest that both conduction aphasia and pure word-deafness have been regarded as stages in the recovery from auditory aphasia. There is certainly in both these conditions the common feature that the ability to repeat words is impaired or destroyed. However, the inner language is intact in pure word-deafness and impaired in conduction aphasia.

One feature in the symptomatology of pure word-deafness is of particular interest in connection with asymbolia for pain. That is the lack of reaction to auditory stimuli. This feature has been considered as due to a lack of attention. We have pointed out that such an interpretation is not correct. In reality these patients are not unattentive in conversation. On the contrary, they are anxious to catch every word and the meaning of every word as soon as they are engaged in conversation. What is really lacking is not the ability to attend, but the reflex turning towards the person speaking or the origin of the noise. This deficiency at once suggests a relation to the lack of adequate reaction to painful, 
visual, and auditory stimuli, characteristic of asymbolia for pain. One is justified in saying that pure word-deafness contains one important feature of asymbolia for pain, and vice versa. This common feature seems to be a lack of the ability to make an appropriate response to stimuli reaching the patient from the outer world. One can maintain that asymbolia for pain is the more primitive and more general symptom, while the lack of response in pure worddeafness is confined to one special group of stimuli.

For the understanding of asymbolia for pain from a biological point of view, it is necessary to note that in the majority of cases asymbolia for pain is combined with some form of word-deafness. All types of word-deafness represent, after all, a loss of relation to the outer world, confined to the lack of understanding of spoken language. The combination of these two symptoms is certainly not accidental, but indicates a deep relation between them, formed by the common loss of certain reactions in human behaviour, biologically important. It was pointed out that in asymbolia for pain the reaction to dangerous stimuli may be either entirely lacking or impaired, although there is no impairment of perception of stimuli. The same seems to be true for pure word-deafness in the acoustic sphere. The failure of our patient, as we have reported, to react adequately to an acoustic warning signal in a situation experienced every day in normal life (we refer to his disregard of a motor horn) shows how vital are the reactions which the patient has lost. For our case it cannot be definitely decided whether this loss of flight reaction was due to the pure word-deafness or the asymbolia for pain. Either condition could be held responsible. This behaviour differs entirely from what is observed in ordinary deafness, where the individual is anxious to respond to every audible sound and indeed tends to react in an exaggerated way to heard warning stimuli. It is difficult to estimate how rare is the combination of pure word-deafness with asymbolia for pain. In the cases reported in the literature there is no evidence to show that the latter symptom was investigated.

As to the site of the lesions responsible for the symptoms in our patient, we are unable to make a definite statement. We have already shown that there was probably a lesion of the left labyrinth which by itself could not explain the pure word-deafness. It is necessary to assume the existence of a cortical lesion. According to the literature, lesions of the middle part of the first temporal convolution of the left hemisphere adjacent to the auditory cortex of Heschl's transverse convolution, have been found in pure word-deafness (Bonvicini, 1905; Liepmann, 1908; Gehuchten and Goris, 1910; Potzl, 1919; Henschen, 1923; Schuster and Taterka, 1926; Goldstein, 1927; Kleist, 1934). These lesions were said to have severed the connection between that part of the first temporal convolution and the auditory cortex. There is no measure of agreement as to what extent the auditory area itself is involved and to what degree the middle part of the first temporal convolution can be regarded as belonging functionally to the auditory area. However, it is significant that in our case there was a traumatic fissure of the left squama ossis temporalis, projecting over the "word-deafness region." There were no signs suggesting a bilateral cortical lesion such as others have reported. 
The existence of asymbolia for pain suggests in itself a certain localization. In a number of cases described the post-mortem examination consistently revealed lesions of the supramarginal gyrus of the left side (Schilder and Stengel, 1928; Potzl and Stengel, 1937). In our case we feel tempted to assume an involvement of this area. Kleist (1934) has described a case of pure worddeafness where a lesion of the left temporal convolution existed with a lesion of the supramarginal gyrus, indicating that such a combination does occur.

The precise nature of the lesion itself cannot be ascertained, but there was undoubtedly a severe trauma to the brain associated with a fracture of part of the temporal bone. It can be assumed that the trauma was followed by a hæmorrhage on or into the substance of the brain. The patient's blood pressure being somewhat high, it is possible that small vessels near the surface of the brain may have been ruptured.

The question of the pure word-deafness in the scheme of aphasias can now be discussed. The answer to this question naturally is bound up with the very definition of aphasia in general. If, according to Head, aphasia is defined as " a lack of the capacity of symbolic formulation and expression," one can hardly regard pure word-deafness as an aphasic disorder. If the disturbance of the inner language is made an essential condition for regarding a speech disorder as an aphasia, pure word-deafness must be rejected from the scheme of aphasia on these grounds. It seems as if the disturbance essential for pure word-deafness involves a function of perception of a higher level than the hearing proper. The supposition that the middle part of the first left temporal convolution, usually involved in pure word-deafness, is to be regarded as an extension of the auditory sensory area (Henschen, 1923), supports the idea that the function lost in pure word-deafness is something which is of a sensory character, although indispensable for understanding of spoken language. Whether one regards this function as part of the speech mechanism or as part of the perceptive sensory process is a theoretical question. The fact that pure word-deafness has been observed in the course of the recovery of a typical auditory aphasia does not determine this question one way or the other. Against the assumption that such a fact is a proof that pure word-deafness represents only a stage in auditory aphasia, it could be argued with equal justice that by the recovery of the auditory aphasia the other symptom is permitted to appear on the surface. In the same way the relationship between auditory aphasia and conduction aphasia could be explained. In conduction aphasia an element of a more peripheral character appears to complicate an auditory aphasia (Stengel, 1933).

\section{Summary}

A case has been described in which there was a syndrome consisting of pure word-deafness and what has been described as asymbolia for pain, following a head injury. The inter-relationship of these two disorders has been discussed and it has been pointed out that pure word-deafness and asymbolia for pain have the common feature of a disturbance in the relationship between the individual and his environment. The localization of the responsible lesions has been 
discussed. Consideration has been given to the problem of the position of pure word-deafness in the systems of aphasias.

We wish to express our gratitude to Dr. J. J. B. Martin, Medical Superintendent of the Bristol City and County Mental Hospital, for permission to publish this case; to Dr. A. J. Wright, Honorary Surgeon to the Ear, Nose and Throat Department of the Bristol General Hospital, for placing the otological findings at our disposal; and to Dr. H. H. Carleton, Honorary Physician to Bristol General Hospital, for giving us the opportunity to examine this case while under his care.

\section{REFERENCES}

Arnaud, H. (1887). Arch. Neurol., 12, 177.

Ballet, G. (1901). Aphasie, Paris.

Bezold, F. (1903). Die funktionelle Prüfung des menschlichen Gehörorgans. Wiesbaden. Bonvicini, G. (1905). Jb. Psychiat., 26, 126.

Frazier, C. S., and Rowe, S. N. (1934). Res. Pbl. Ass. nerv. ment. Dis., 13, 251.

Freund, C. S. (1903). Labyrinthtaubheit und Sprachtaubheit. Wiesbaden.

Gehuchten, Van, and Goris (1910). Quoted by Bonvicini.

Goldstein, K. (1927). Handb. Physiol., 10, 775.

Head, H. (1926). Aphasia and Kindred Disorders. Macmillan, Cambridge.

Henschen, S. E. (1923). Pathologie des Gehirns. Stockholm.

Hoff, H., and Silbermann, M. (1933). Z. ges. Neurol. Psychiat., 144, 675.

Jackson, Hughlings (1935). Selected papers. London.

Kleist, K. (1934). Gehirnpathologie. Leipzig.

Lichtheim, L. (1885). Arch. klin. Med., 36, 204.

Liepmann, H. (1898). Psychiat. Abhandl., Breslau.

Marie, Pierre (1926). Travaux et mémoires. Massou, Paris.

Mourgue, R. (1920). Encéphale, 15, 649.

Pötzl, O. (1919). Reine Worttaubheit. Berlin.

Pötzl, O., and Stengel, E. (1937). Jb. Psychiat., 53, 174.

Schilder, P., and Stengel, E. (1928a). Z. ges. Neurol. Psychiat., 113, 143. (1928b). Klin. Wschr., 7, 535.

(1930). Z. ges. Neurol. Psychiat., 129, 250.

(1931). Arch. Neurol. Psychiat., 25, 598.

Schuster, P., and Taterka, H. (1926). Z. ges. Neurol. Psychiat., 105, 494.

Silbermann, M., and Tamari, M. (1937). Jb. Psychiat., 50, 98.

Stengel, E. (1933). Z. ges. Neurol. Psychiat., 149, 266.

Weisenburg, T., and MacBride, K. E. (1937). Aphasia. New York.

Wernicke, C. (1874). Der aphasische Symptomenkomplex. Cohn and Weigest, Breslau.

Woerkom, W. van (1925). Mschr. Psychiat. Neurol., 59, 256.

Wyllie, J. (1894). The Disorders of Speech. Edinburgh. 